\title{
CDISC SEND Fetal Measurement Test Code Terminology
}

National Cancer Institute

\section{Source}

National Cancer Institute. CDISC SEND Fetal Measurement Test Code Terminology. NCI

Thesaurus. Code C124311.

Terminology associated with the fetal measurement test code codelist of the Clinical Data Interchange Standards Consortium (CDISC) Standard for the Exchange of Nonclinical data (SEND). 